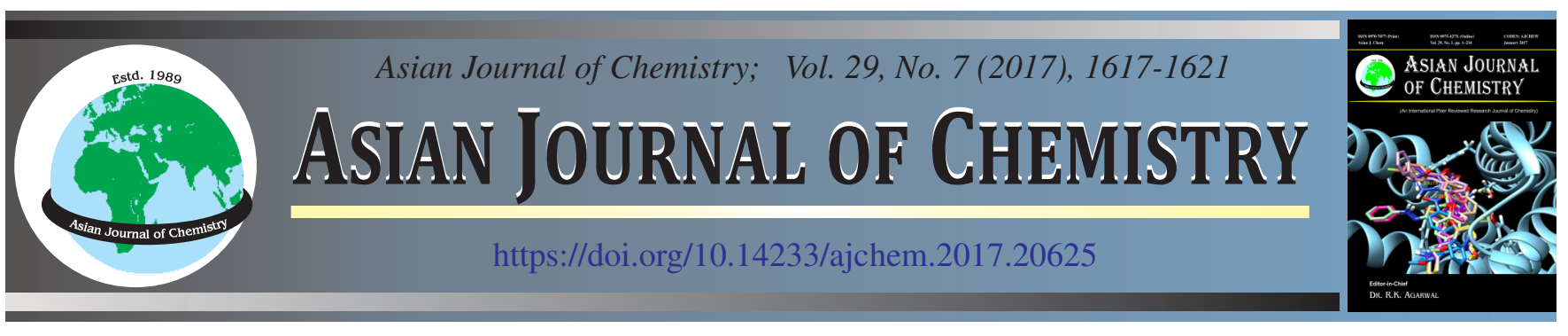

\title{
Kinetics and Thermodynamics of Oxidation of Some para-Substituted 4-Oxo-4-phenyl Butanoic Acids by Tripropylammonium Fluorochromate in Aqueous Acetic Acid Medium
}

\author{
A. Yogananth ${ }^{1}$, Basim H. Asghar ${ }^{2}$ and S. Sheik Mansoor ${ }^{3, *}$
}

${ }^{1}$ Research and Development Centre, Bharathiar University, Coimbatore-641 046, India

${ }^{2}$ Department of Chemistry, Faculty of Applied Sciences, Umm Al-Qura University, P.O. Box: 9569, Makkah, Saudi Arabia

${ }^{3}$ Department of Chemistry, C. Abdul Hakeem College (Autonomous), Melvisharam-632 509, India

*Corresponding author: E-mail: smansoors2000@yahoo.co.in

The kinetics of oxidation of 4-oxo-4-phenyl butanoic acid (4-oxo acid), $p$-methoxy $\left(p-\mathrm{OCH}_{3}\right), p$-ethoxy $\left(p-\mathrm{OC}_{2} \mathrm{H}_{5}\right), p$-methyl $\left(p-\mathrm{CH}_{3}\right), p$ chloro $(p-\mathrm{Cl}), p$-bromo $(p-\mathrm{Br})$ and $p$-acetyl $\left(p-\mathrm{COCH}_{3}\right)$ 4-oxo acids by tripropylammonium fluorochromate (TriPAFC) in aqueous acetic acid medium in the presence of perchloric acid have been described. The reaction is first order with respect to 4-oxo acid, TriPAFC and perchloric acid. The order of reactivity among the studied 4-oxoacids is: $p-\mathrm{OCH}_{3}>p-\mathrm{OC}_{2} \mathrm{H}_{5}>p-\mathrm{CH}_{3}>p-\mathrm{H}>p-\mathrm{Cl}>p-\mathrm{Br}>p-\mathrm{COCH}$. The effect of changes on the electronic nature of the substrate reveals that there is a development of positive charge in the transition state. The activation parameters have been computed from Arrhenius and Eyring plots. Based on the kinetic results, a suitable mechanism has been proposed.

Keywords: Tripropylammonium fluorochromate, 4-Oxo acid, Thermodynamic parameters, Kinetics.

ᄂ - - - - - - - - - - - - - - - - - - - - - - - - - - - -

\section{INTRODUCTION}

In modern organic synthesis the oxidation of an organic substrate is important. Therefore, synthetic organic chemists pay attention to search for new oxidizing reagents [1]. In recent years, extensive works have led to the development of a good number of chromium(VI) oxidizing agents such as isoquinolinium fluorochromate [2], tetramethylammonium fluorochromate [3], isoquinolinium bromochromate [4], tetrahexylammonium bromochromate [5], tributylammonium chlorochromate [6] and tetrabutylammonium bromochromate [7] to study the oxidation of various organic compounds.

Organic chemists must often choose from hundreds of oxidizing agents and reaction conditions to perform a desired oxidation without affecting other functional groups present or causing side reactions. Although there are a broad variety of oxidants derived from $\mathrm{Cr}(\mathrm{VI})$ reported in literature to perform oxidation reactions tripropylammonium fluorochromate reported as an efficient oxidizing agent [8-11].

The oxidation kinetics of 4-oxo acids by various oxidizing agents like permanganate [12], pyridinium fluorochromate [13], $\mathrm{N}$-bromosuccinimide [14], $\mathrm{N}$-chlorosaccharin [15], $\mathrm{N}$ bromosaccharin [16], $N$-chlorobenzamide [17] and benzimidazolium fluorochromate [18] have been extensively studied by various workers.
Even though, numerous oxidants for oxidation of 4-oxo acids are already reported, as a part of our continuing investigations of the oxidation of organic substrates using $\mathrm{Cr}$ (VI) reagents [19-23], this work reports the kinetic features of the oxidation of 4-oxo acid by tripropylammonium fluorochromate.

\section{EXPERIMENTAL}

All the chemicals used were reagent grade products. Tripropylammonium fluorochromate (TriPAFC) was prepared by a reported method [9]. Acetic acid was purified by standard method and the fraction distilling at $118{ }^{\circ} \mathrm{C}$ was collected.

Preparation of 4-oxo-4-phenyl butanoic acid: The 4-oxo-4-phenyl butanoic acid is synthesized by the FriedelCraft's reaction between succinic anhydride and benzene in the presence of anhydrous aluminium chloride [12].

Kinetic measurements: Solutions were prepared in double-distilled water. The reaction mixtures, containing oxo acid, acetic acid and perchloric acid solutions, were thermally equilibrated for $1 \mathrm{~h}$ at the desired temperature. The reaction was initiated by the addition of a temperature-equilibrated TriPAFC solution of the requisite concentration. The rate was studied spectrophotometrically by monitoring the disappearance of [TriPAFC] at $362 \mathrm{~nm}$ using UV-vis spectrophotometer, Shimadzu UV-1800 model in $50 \%$ acetic acid - $50 \%$ water 
$(\mathrm{v} / \mathrm{v})$. All of the reactions were carried out under pseudo-firstorder conditions by keeping an excess (tenfold or greater) of [4-oxo acid] over TriPAFC] i.e. [4-oxo acid] >> [TriPAFC)]. The pseudo-first-order rate constants $\left(\mathrm{k}_{1}\right)$ were computed from linear plots of log [TriPAFC] against time up to $90 \%$ completion of the reaction. The precision of the rate constant values is given in terms of $95 \%$ the confidence limit of the student's t test [24] and the values were reproducible to within $5 \%$.

Product analysis and stoichiometric studies: The products in the respective oxidation of 4-oxo acids were corresponding benzoic acids and this were confirmed by comparing the melting point values.

The stoichiometric studies showed that 1 mol of TriPAFC reacts with $1 \mathrm{~mol}$ of 4-oxo-4-phenyl butanic acid.

\section{RESULTS AND DISCUSSION}

Order of the reaction: The oxidation of organic compounds with high selectivity is of extreme importance in synthetic chemistry. Reactions were carried out under pseudo first-order conditions with a known excess of [4-oxo acids] over [TriPAFC] at constant temperature of $303 \mathrm{~K}$ in $50 \%$ acetic acid and $50 \%$ water medium.

The values of $k_{1}$ were independent of the initial concentration of TriPAFC (Table-1) suggesting the reactions were of first order with respect to TriPAFC. The reaction was catalyzed by hydrogen ions and the order with respect to $\left[\mathrm{H}^{+}\right]$was one.

The $\mathrm{k}_{1}$ values measured at various initial concentrations of 4-oxo acid for the oxidation show a linear increase (Table-1). The plot of $\log \mathrm{k}_{1}$ versus $\log$ [4-oxo acid] is excellently linear $(\mathrm{r}=0.999)$ with unit slope, indicating that the order of the reaction with respect to [4-oxo acid] is one (Fig. 1). This is further evidenced by the excellent linearity observed in the plot of $\mathrm{k}_{1}$ versus [4-oxo acid], which passes through origin (Fig. 2).

Effect of acrylonitrile and $\mathrm{MnSO}_{4}$ : The involvement of free-radical intermediates in the present study can be excluded, as the rate constant is not affected by the addition of acrylonitrile. The addition of $\mathrm{Mn}(\mathrm{II})$, indicating the involvement of a two-electron reduction of $\mathrm{Cr}(\mathrm{VI})$ to $\mathrm{Cr}(\mathrm{IV})$ (Table-1).



Fig. 1. Double logarithmic plot for the oxidation of $p$-substituted 4-oxo4-phenyl-butanoic acids with TriPAFC

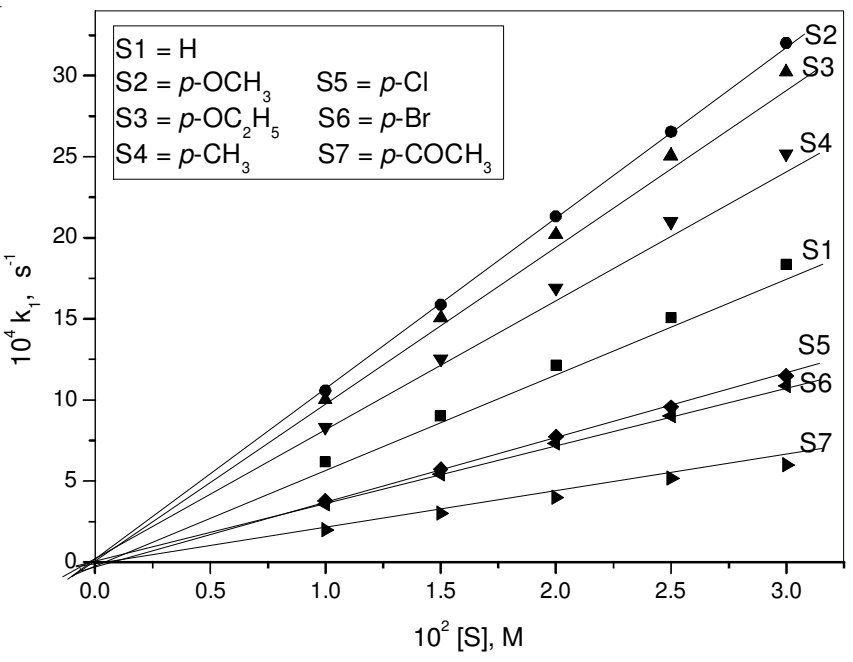

Fig. 2. Direct plot for the oxidation of $p$-substituted 4-oxo-4-phenylbutanoic acids with TriPAFC

\begin{tabular}{|c|c|c|c|c|c|c|c|c|c|}
\hline \multirow{3}{*}{$\begin{array}{l}10^{3}[\text { TriPAFC }] \\
\left(\mathrm{mol} \mathrm{dm}^{-3}\right)\end{array}$} & \multicolumn{8}{|c|}{$\begin{array}{c}\text { TABLE-1 } \\
\text { EFFECT OF VARIATION OF [S], [TriPAFC] AND }\left[\mathrm{H}^{+}\right] \text {ON THE RATE OF REACTION AT } 303 \mathrm{~K}^{\mathrm{a}}\end{array}$} & \\
\hline & \multirow{2}{*}{$\begin{array}{c}10^{2}[\mathrm{~S}] \\
\left(\mathrm{mol} \mathrm{dm} \mathrm{dm}^{-3}\right)\end{array}$} & \multirow{2}{*}{$\begin{array}{c}{\left[\mathrm{H}^{+}\right]} \\
\left(\mathrm{mol} \mathrm{dm}^{-3}\right)\end{array}$} & \multicolumn{7}{|c|}{$10^{4} \mathrm{k}_{1}\left(\mathrm{~s}^{-1}\right)^{\mathrm{b}}$} \\
\hline & & & $\mathrm{H}$ & $p-\mathrm{OCH}_{3}$ & $p-\mathrm{OC}_{2} \mathrm{H}_{5}$ & $p-\mathrm{CH}_{3}$ & $p-\mathrm{Cl}$ & $p-\mathrm{Br}$ & $p-\mathrm{COCH}_{3}$ \\
\hline 0.6 & 2.0 & 0.26 & 12.18 & 23.52 & 22.26 & 18.80 & 7.88 & 7.34 & 3.80 \\
\hline 1.1 & 2.0 & 0.26 & 12.26 & 23.60 & 22.32 & 18.88 & 7.82 & 7.40 & 3.88 \\
\hline 1.6 & 2.0 & 0.26 & 12.30 & 23.64 & 22.40 & 18.96 & 7.76 & 7.42 & 3.98 \\
\hline 2.1 & 2.0 & 0.26 & 12.22 & 23.66 & 22.38 & 18.84 & 7.90 & 7.38 & 3.90 \\
\hline 2.6 & 2.0 & 0.26 & 12.32 & 23.56 & 22.30 & 18.92 & 7.74 & 7.44 & 3.84 \\
\hline 1.1 & 1.2 & 0.26 & 7.52 & 14.04 & 13.30 & 11.26 & 4.66 & 4.38 & 2.28 \\
\hline 1.1 & 1.6 & 0.26 & 9.68 & 18.78 & 17.78 & 15.02 & 6.18 & 5.86 & 3.04 \\
\hline 1.1 & 2.4 & 0.26 & 14.86 & 28.30 & 26.76 & 22.60 & 9.30 & 8.78 & 4.60 \\
\hline 1.1 & 2.8 & 0.26 & 17.04 & 33.00 & 31.16 & 26.36 & 10.84 & 10.30 & 5.36 \\
\hline 1.1 & 2.0 & 0.10 & 4.78 & 9.04 & 8.50 & 7.18 & 3.00 & 2.80 & 1.46 \\
\hline 1.1 & 2.0 & 0.18 & 8.30 & 16.26 & 15.36 & 13.00 & 5.40 & 5.06 & 2.66 \\
\hline 1.1 & 2.0 & 0.34 & 15.90 & 30.78 & 29.10 & 24.60 & 10.16 & 9.56 & 5.04 \\
\hline 1.1 & 2.0 & 0.26 & $12.30^{\mathrm{c}}$ & $23.48^{\mathrm{c}}$ & $22.26^{\mathrm{c}}$ & $18.72^{\mathrm{c}}$ & $7.78^{\mathrm{c}}$ & $7.28^{c}$ & $3.72^{c}$ \\
\hline 1.1 & 2.0 & 0.26 & $10.68^{d}$ & $19.98^{\mathrm{d}}$ & $18.92^{\mathrm{d}}$ & $15.64^{d}$ & $6.72^{d}$ & $6.18^{d}$ & $3.16^{\mathrm{d}}$ \\
\hline
\end{tabular}

${ }^{\mathrm{a}}$ As determined by spectrophotometrically following the disappearance of $\mathrm{Cr}(\mathrm{VI})$ at $362 \mathrm{~nm}$; ${ }^{\mathrm{b}}$ Estimated from pseudo first order plots; ${ }^{\mathrm{c}}$ In the presence of $0.001 \mathrm{~mol} \mathrm{dm}^{-3}$ acrylonitrile; ${ }^{\mathrm{d}}$ In the presence of $0.003 \mathrm{~mol} \mathrm{dm}^{-3} \mathrm{Mn}(\mathrm{II})$; Solvent composition $=50 \% \mathrm{AcOH}-50 \% \mathrm{H}_{2} \mathrm{O}(v / v)$ 


\begin{tabular}{|c|c|c|c|c|c|c|c|c|}
\hline \multirow{3}{*}{$\begin{array}{l}\% \text { AcOH- } \\
\mathrm{H}_{2} \mathrm{O}(\mathrm{v} / \mathrm{v})\end{array}$} & \multicolumn{7}{|c|}{$\begin{array}{c}\text { TABLE-2 } \\
\text { EFFECT OF VARYING SOLVENT POLARITY ON THE RATE OF REACTION OF 4-OXO ACID, } \\
p-\mathrm{OCH}_{3}, p-\mathrm{OC}_{2} \mathrm{H}_{5}, p-\mathrm{CH}_{3}, p-\mathrm{Cl}, p-\mathrm{Br} \text { AND } p \mathrm{COCH}_{3} 4-\mathrm{OXO} \text { ACIDS BY TriPAFC AT } 303 \mathrm{~K}\end{array}$} & \\
\hline & \multirow{2}{*}{$\begin{array}{c}\text { Dielectric } \\
\text { constant }\end{array}$} & \multicolumn{7}{|c|}{$10^{4} \mathrm{k}_{1}\left(\mathrm{~s}^{-1}\right)$} \\
\hline & & $\mathrm{H}$ & $p-\mathrm{OCH}_{3}$ & $p-\mathrm{OC}_{2} \mathrm{H}_{5}$ & $p-\mathrm{CH}_{3}$ & $p-\mathrm{Cl}$ & $p-\mathrm{Br}$ & $p-\mathrm{COCH}_{3}$ \\
\hline $30-70$ & 72.0 & 9.72 & 18.66 & 17.66 & 15.12 & 6.16 & 5.84 & 3.08 \\
\hline $40-60$ & 63.3 & 11.00 & 21.16 & 20.04 & 16.94 & 7.04 & 6.68 & 3.45 \\
\hline $50-50$ & 56.0 & 12.26 & 23.60 & 22.32 & 18.88 & 7.82 & 7.40 & 3.88 \\
\hline $60-40$ & 45.5 & 14.22 & 27.32 & 26.36 & 21.96 & 9.16 & 8.68 & 4.52 \\
\hline $70-30$ & 38.5 & 17.63 & 33.92 & 32.66 & 26.96 & 11.16 & 10.64 & 5.64 \\
\hline
\end{tabular}

Effect of solvent polarity: In binary mixtures of acetic acid and water as solvent, the rate of the reaction increases remarkably with an increase in the proportion of acetic acid in the medium (Table-2). The concentration of acetic acid was varied from 30 to $70 \%$ and the rate were measured. When the acetic acid content is increased, the acidity of the medium increases, while the dielectric constant of the medium decreases. These two effects cause the rate of the oxidation to increase remarkably. A plot of $\log \mathrm{k}_{1}$ versus 1/D has been given in Fig. 3 . The linear plot obtained indicates that the involvement of cation-dipole type of interaction in the rate determining step [25].

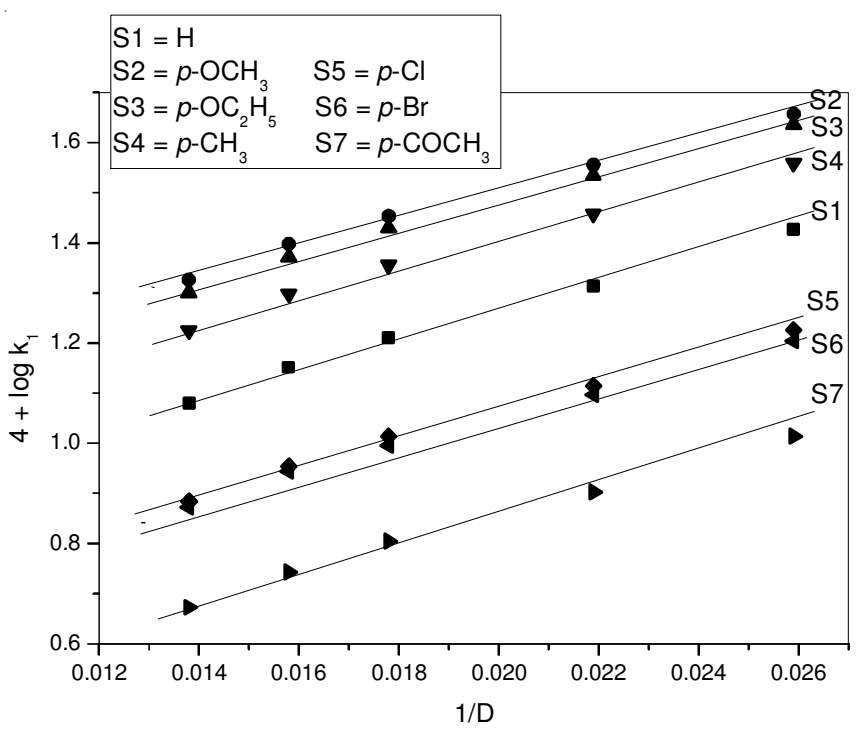

Fig. 3. Amis plot for the reaction between para-substituted 4-oxo-4-phenylbutanoic acids by TriPAFC between $4+\log \mathrm{k}_{1}$ and 1/D

Activation parameters: The first-order rate constants for the oxidation of the selected oxo acids with TriPAFC at four different temperatures are collected in Table- 3 . The secondorder rate constants and activation parameters were calculated and the values were presented in Table- 4 .

TABLE-3

PSEUDO-FIRST ORDER RATE CONSTANTS FOR THE OXIDATION OF 4-OXO ACID, $p$ - $\mathrm{OCH}_{3}, p-\mathrm{OC}_{2} \mathrm{H}_{5}, p-\mathrm{CH}_{3}, p-\mathrm{Cl}$, $p$-Br AND $p$ - $\mathrm{COCH}_{3} 4$-OXO ACIDS BY TriPAFC AT VARIOUS TEMPERATURES IN AQUEOUS ACETIC ACID MEDIUM

\begin{tabular}{lcccc}
\hline \multirow{2}{*}{ Substrate } & \multicolumn{4}{c}{$10^{4} \mathrm{k}_{1}\left(\mathrm{~s}^{-1}\right)$} \\
\cline { 2 - 5 } & $298 \mathrm{~K}$ & $303 \mathrm{~K}$ & $308 \mathrm{~K}$ & $313 \mathrm{~K}$ \\
\hline $\mathrm{H}$ & 8.08 & 12.26 & 17.22 & 24.30 \\
$p-\mathrm{OCH}_{3}$ & 17.60 & 23.60 & 31.56 & 42.32 \\
$p-\mathrm{OC}_{2} \mathrm{H}_{5}$ & 16.40 & 22.32 & 30.34 & 41.28 \\
$p-\mathrm{CH}_{3}$ & 13.64 & 18.88 & 26.12 & 35.92 \\
$p-\mathrm{Cl}$ & 5.36 & 7.82 & 11.32 & 16.44 \\
$p-\mathrm{Br}$ & 5.04 & 7.40 & 10.80 & 15.74 \\
$p-\mathrm{COCH}$ & 2.64 & 3.88 & 5.74 & 8.48 \\
\hline $10^{2}[\mathrm{~S}]=2.0 \mathrm{~mol} \mathrm{dm}^{-3} ; 10^{3}[$ TriPAFC $]=1.1 \mathrm{~mol} \mathrm{dm}^{-3} ; 10\left[\mathrm{H}^{+}\right]=2.6$ \\
mol dm $^{-3} ;$ Solvent composition $=50 \% \mathrm{AcOH}-50 \% \mathrm{H}_{2} \mathrm{O}(\mathrm{v} / \mathrm{v})$
\end{tabular}

Effect of substituents-Hammett plot: Electron-releasing substituents in the phenyl ring accelerate the rate, while electronwithdrawing substituents produce the opposite effect [26]. The $\log \mathrm{k}_{2}$ values show excellent correlation with the $\sigma_{\mathrm{p}}$ values. The $\rho$ values calculated from the slopes of the Hammett plots at the four different temperatures are also included in Table-5. A negative value of $\rho$ indicates an accumulation of positive charge at the reaction carbon center.

The effect of structure on reactivity of para-substituted 4-oxo acids were studied. It is interesting to note that the reactivity decreases in the order $p-\mathrm{OCH}_{3}>p-\mathrm{OC}_{2} \mathrm{H}_{5}>p-\mathrm{CH}_{3}>$ $p-\mathrm{H}>p-\mathrm{Cl}>p-\mathrm{Br}>p-\mathrm{COCH}_{3}$ for the substituents.

Mechanism of oxidation: The negative $\rho$ value obtained from the Hammett plot indicates the formation of a carbocation in the rate-determining step. The activation parameters are of the order expected for a bimolecular substitution reaction. The

TABLE-4

ACTIVATION PARAMETERS AND SECOND ORDER RATE CONSTANTS FOR THE OXIDATION OF 4-OXO ACID, $p-\mathrm{OCH}_{3}, p-\mathrm{OC}_{2} \mathrm{H}_{5}, p-\mathrm{CH}_{3}, p$-Cl, $p$-Br AND $p$ - $\mathrm{COCH}_{3} 4$-OXO ACIDS BY TriPAFC IN AQUEOUS ACETIC ACID MEDIUM

\begin{tabular}{|c|c|c|c|c|c|c|c|c|}
\hline \multirow{2}{*}{ Substrate } & \multicolumn{4}{|c|}{$10^{2} \mathrm{k}_{2}\left(\mathrm{dm}^{3} \mathrm{~mol}^{-1} \mathrm{~s}^{-1}\right)$} & \multirow{2}{*}{$\begin{array}{c}\mathrm{E}_{\mathrm{a}} \\
\left(\mathrm{kJ} \mathrm{mol}^{-1}\right)\end{array}$} & \multirow{2}{*}{$\begin{array}{c}\Delta \mathrm{H}^{\#} \\
\left(\mathrm{~kJ} \mathrm{~mol}^{-1}\right)\end{array}$} & \multirow{2}{*}{$\begin{array}{c}-\Delta \mathrm{S}^{\#} \\
\left(\mathrm{JK}^{-1} \mathrm{~mol}\right)\end{array}$} & \multirow{2}{*}{$\begin{array}{c}\Delta \mathrm{G}^{\#}\left(\mathrm{~kJ} \mathrm{~mol}^{-1}\right) \\
(\text { at } 303 \mathrm{~K})\end{array}$} \\
\hline & $298 \mathrm{~K}$ & $303 \mathrm{~K}$ & $308 \mathrm{~K}$ & $313 \mathrm{~K}$ & & & & \\
\hline $\mathrm{H}$ & 4.04 & 6.13 & 8.61 & 12.15 & 56.07 & $54.78 \pm 0.2$ & $92.07 \pm 0.6$ & $82.64 \pm 0.4$ \\
\hline$p-\mathrm{OCH}_{3}$ & 8.80 & 11.80 & 15.78 & 21.16 & 45.38 & $42.88 \pm 0.6$ & $120.98 \pm 1.8$ & $79.53 \pm 1.2$ \\
\hline$p-\mathrm{OC}_{2} \mathrm{H}_{5}$ & 8.20 & 11.16 & 15.17 & 20.64 & 47.86 & $45.37 \pm 0.4$ & $113.71 \pm 1.2$ & $79.82 \pm 0.8$ \\
\hline$p-\mathrm{CH}_{3}$ & 6.82 & 9.44 & 13.06 & 17.96 & 50.16 & $47.67 \pm 0.2$ & $107.20 \pm 0.6$ & $80.15 \pm 0.4$ \\
\hline$p-\mathrm{Cl}$ & 2.68 & 3.91 & 5.61 & 8.22 & 57.82 & $55.33 \pm 0.4$ & $69.20 \pm 1.2$ & $82.36 \pm 0.8$ \\
\hline$p-\mathrm{Br}$ & 2.52 & 3.70 & 5.40 & 7.87 & 58.96 & $56.48 \pm 0.6$ & $86.14 \pm 1.8$ & $82.58 \pm 1.2$ \\
\hline$p-\mathrm{COCH}_{3}$ & 1.32 & 1.94 & 2.87 & 4.24 & 60.69 & $58.01 \pm 0.3$ & $84.98 \pm 0.9$ & $83.76 \pm 0.6$ \\
\hline
\end{tabular}

$10^{2}[\mathrm{~S}]=2.0 \mathrm{~mol} \mathrm{dm}^{-3} ; 10^{3}[\mathrm{TriPAFC}]=1.1 \mathrm{~mol} \mathrm{dm}^{-3} ; 10\left[\mathrm{H}^{+}\right]=2.6 \mathrm{~mol} \mathrm{dm}^{-3} ;$ Solvent composition $=50 \%$ AcOH $-50 \% \mathrm{H}_{2} \mathrm{O}(\mathrm{v} / \mathrm{v})$ 


\begin{tabular}{|c|c|c|c|}
\hline \multicolumn{4}{|c|}{$\begin{array}{c}\text { TABLE-5 } \\
\text { REACTION CONSTANT VALUES FOR THE OXIDATION OF } \\
\text { 4-OXO ACID, } p \text {-OCH }{ }_{3}, p-\mathrm{OC}_{2} \mathrm{H}_{5}, p \text { - } \mathrm{CH}_{3}, p \text {-Cl, } p \text {-Br AND } p \text {-COCH }{ }_{3} \\
\text { 4-OXO ACIDS BY TriPAFC IN AQUEOUS ACETIC ACID } \\
\text { MEDIUM AT DIFFERENT TEMPERATURES }\end{array}$} \\
\hline $\begin{array}{l}\text { Temperature } \\
\text { (K) }\end{array}$ & $\begin{array}{l}\text { Reaction } \\
\text { constant }(\rho)\end{array}$ & $\begin{array}{l}\text { Correlation } \\
\text { coefficient }\end{array}$ & $\begin{array}{l}\text { Standard } \\
\text { deviation }\end{array}$ \\
\hline 298 & -1.0598 & 0.997 & 0.18 \\
\hline 303 & -1.0091 & 0.992 & 0.05 \\
\hline 308 & -0.9543 & 0.988 & 0.11 \\
\hline 313 & -0.8978 & 0.987 & 0.12 \\
\hline
\end{tabular}

large negative entropy of activation suggests that the transition state is more suitably oriented than the reactants as the chargeseparated transition state becomes solvated by a sheath of solvent molecules. The reaction rate increases linearly with the increase in $\left[\mathrm{H}^{+}\right]$ion and hence protonated TriPAFC is formed. The rate enhancement observed in the present study

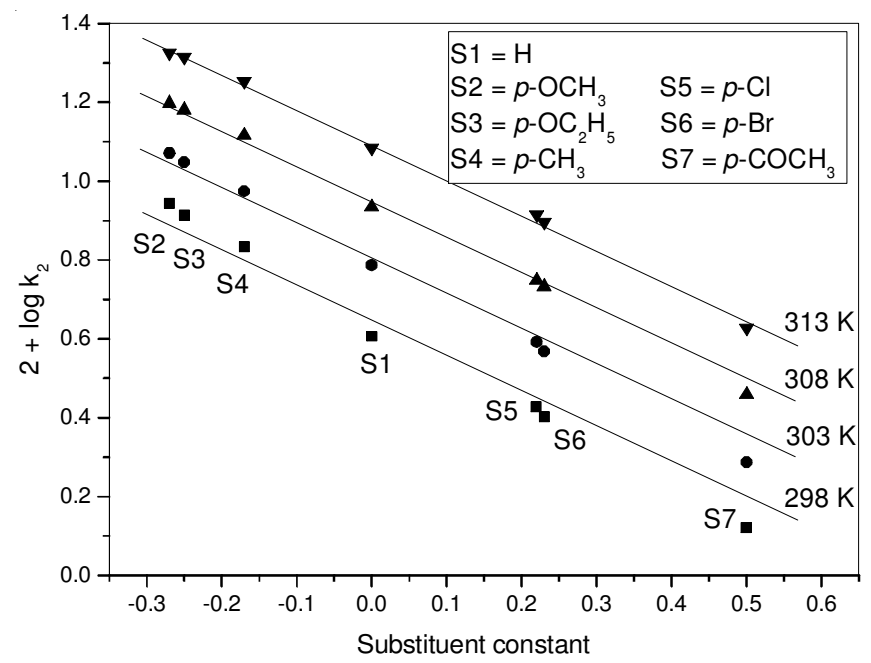

Fig. 4. Hammett plot of $\log \mathrm{k}_{2}$ versus substituent constant $\sigma_{\mathrm{p}}$ for the oxidation of $p$-substituted 4-oxo-4-phenyl-butanoic acids with TriPAFC in aqueous acetic acid medium at different temperatures
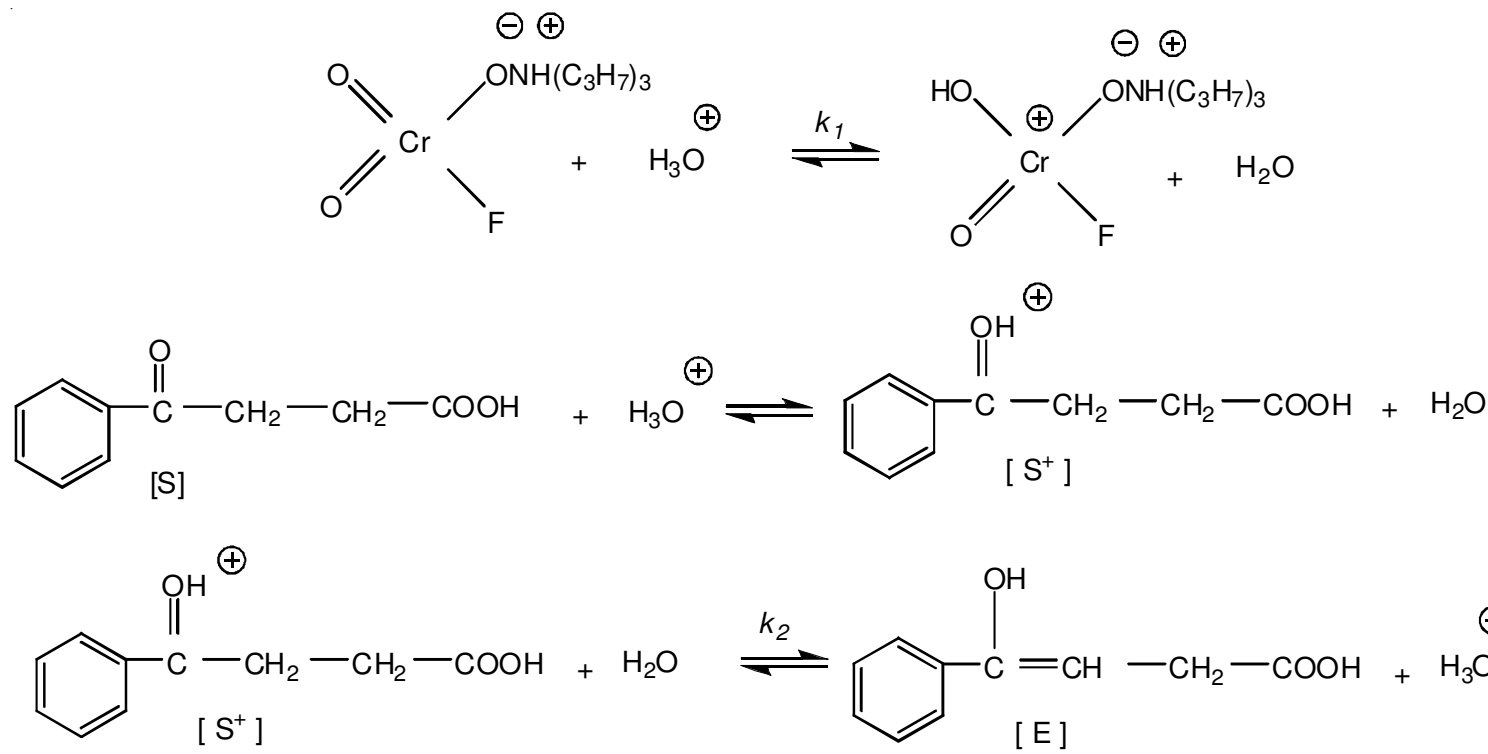<smiles>[Y20]C1C=CCC1</smiles>

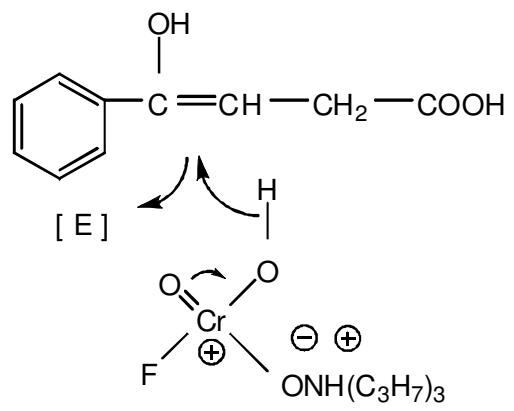<smiles></smiles>

[ F ]



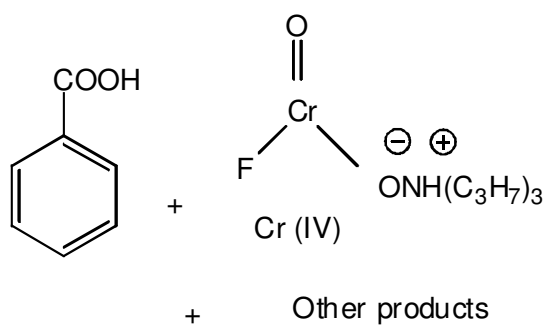

[ F ]

Scheme-I: Mechanism of oxidation of 4-oxo acid by TriPAFC 
with increase in the acetic acid content of the solvent medium establishes the involvement of the enol form of the oxo acid in the reaction, as the enolization of a keto group is facilitated by a lowering of the dielectric constant of the medium. Based on these kinetic observations, the following mechanism (SchemeI) is proposed.

The above mechanism leads to the following rate law:

$$
-\mathrm{d}\left[\text { TriPAFC] } / \mathrm{dt}=\mathrm{k}_{1} \mathrm{k}_{2} \mathrm{k}_{3} \text { [4-oxo acid] [TriPAFC] }\left[\mathrm{H}^{+}\right]\right.
$$

\section{Conclusion}

In this paper, the detailed mechanism of oxidation of 4oxo acid and some para-substituted 4-oxo acid by TriPAFC is reported. The reaction is first order each in [4-oxo acid], [TriPAFC] and $\left[\mathrm{H}^{+}\right]$. The oxidation of para-substituted 4-oxo acids yield the corresponding benzoic acids. The negative $\rho$ values obtained from the Hammett plot reveals that a positively charged reactive intermediate is formed during the oxidation process. Similarly, the negative value of $\Delta S^{\#}$ provided support for the formation of activated complex in the slow step.

\section{ACKNOWLEDGEMENTS}

One of the authors (A. Yogananth) expresses his gratitude to Research and Development Centre, Bharathiar University, Coimbatore, India, for the facilities and support. The author Mansoor is thankful to the Management of C. Abdul Hakeem College (Autonomous), Melvisharam, India for the support.

\section{REFERENCES}

1. W.B. Wiberg, Oxidation in Organic Chemisry, Academic Press, New York (1995).

2. R. Srinivasan, P. Stanley and K. Balasubramanian, Synth. Commun., 27, 2057 (1997); https://doi.org/10.1080/00397919708006810.

2. G. Ghammamy, K. Mehrani, H.Afrand, Z. Javanshir, G.R. Rezaeibehbahani, A. Moghimi and Z.S. Aghbolagh, J. Chil. Chem. Soc., 54, 491 (2009); https://doi.org/10.4067/S0717-97072009000400038.

3. B. Sadeghy and S. Ghammami, Russ. J. Gen. Chem., 75, 1886 (2005); https://doi.org/10.1007/s11176-006-0008-0.

4. S.V. Khansole, S.B. Patwari, A.Y. Vibhute and Y.B. Vibhute, Chin. Chem. Lett., 20, 256 (2009); https://doi.org/10.1016/j.cclet.2008.11.015
5. S.S. Mansoor and B.H. Asghar, J. Indian Chem. Soc., 90, 1395 (2013).

6. S.S. Mansoor and S.S. Shafi, React. Kinet. Mech. Catal., 100, 21 (2010); https://doi.org/10.1007/s11144-010-0148-4.

7. G. Ghammamy, K. Mehrani, H. Afrand and M. Hajighahrammani, Afr. J. Pure Appl. Chem., 1, 8 (2007).

8. K. Mahanpour, S. Ghammamy, R. Rahimi, S. Asili, F. Siavoshifar, F. Imani and A. Hematimoghadam, Asian J. Chem., 21, 4404 (2009).

9. S. Ghammamy, S. Khorsandtabar, A. Moghimi and H. Sahebalzamani, J. Mex. Chem. Soc., 53, 41 (2009).

10. S.S. Mansoor and S.S. Shafi, J. Mol. Liq., 155, 85 (2010); https://doi.org/10.1016/j.molliq.2010.05.012.

11. S.S. Mansoor, E-J. Chem., 8, 643 (2011); https://doi.org/10.1155/2011/945236.

12. G. Sikkandar and K.A.B. Ahmed, Indian J. Chem., 38A, 183 (1999).

13. S. Kavitha, A. Pandurangan and I. Alphonse, Indian J. Chem., 44A, 715 (2005).

14. N.A.M. Farook, J. Iranian Chem. Soc., 3, 378 (2006); https://doi.org/10.1007/BF03245962.

15. N.A.M. Farook, J. Solution Chem., 36, 345 (2007); https://doi.org/10.1007/s10953-006-9116-Z.

16. N.A.M. Farook, S. Manochitra and A.A. Banu, J. Solution Chem., 42, 239 (2013); https://doi.org/10.1007/s10953-012-9942-0.

17. N.A.M. Farook and G.A.S. Dameem, E-J. Chem., 8, 561 (2011); https://doi.org/10.1155/2011/697973.

18. S.S. Mansoor, S.S. Shafi and S.Z. Ahmed, Arab. J. Chem., 9, S557 (2016); https://doi.org/10.1016/j.arabjc.2011.06.026.

19. S.Z. Ahmed, S.S. Shafi and S.S. Mansoor, Asian J. Chem., 25, 8245 (2013); https://doi.org/10.14233/ajchem.2013.13559.

20. S. Hemalatha, B.H. Asghar and S.S. Mansoor, Asian J. Chem., 29, 810 (2017); https://doi.org/10.14233/ajchem.2017.20318.

21. S.S. Mansoor, V.S. Malik, K. Aswin, K. Logaiya and A.M. Hussain, J. Saudi Chem. Soc., 20, S77 (2016); https://doi.org/10.1016/j.jscs.2012.09.013.

22. V.S. Malik, B.H. Asghar and S.S. Mansoor, J. Taibah Univ. Sci., 10, 131 (2016); https://doi.org/10.1016/j.jtusci.2015.05.009.

23. S.S. Mansoor and S.S. Shafi, Arab. J. Chem., 8, 480 (2015); https://doi.org/10.1016/j.arabjc.2011.01.031.

24. C. Srinivasan, S. Rajagopal and A. Chellamani, J. Chem. Soc., Perkin Trans. II, 1839 (1990); https://doi.org/10.1039/p29900001839.

25. E.S. Amis, Solvent Effects on Reaction Rates and Mechanisms, Academic Press, New York, p. 42 (1967).

26. L.P. Hammett, Physical Organic Chemistry, McGraw-Hill, New York, edn 1 (1940). 